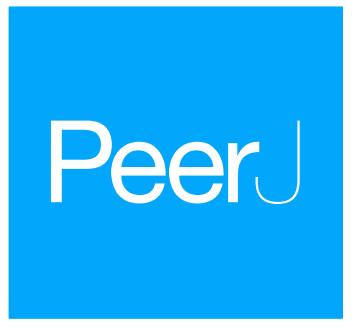

Submitted 8 June 2018

Accepted 10 October 2018

Published 14 November 2018

Corresponding author

Jia-Yong Zhang,

zhangjiayong@zjnu.cn

Academic editor

Daniel Lahr

Additional Information and

Declarations can be found on page 12

DOI 10.7717/peerj.5914

(c) Copyright

2018 Gao et al.

Distributed under

Creative Commons CC-BY 4.0

OPEN ACCESS

\section{Characteristics of the complete mitochondrial genome of Suhpalacsa longialata (Neuroptera, Ascalaphidae) and its phylogenetic implications}

\author{
Xin-Yan $\mathrm{Gao}^{1, *}$, Yin-Yin Cai ${ }^{1, *}$, Dan-Na $\mathrm{Yu}^{1,2}$, Kenneth B. Storey ${ }^{3}$ and \\ Jia-Yong Zhang ${ }^{1,2}$ \\ ${ }^{1}$ College of Chemistry and Life Science, Zhejiang Normal University, Jinhua, Zhejiang, China \\ ${ }^{2}$ Key Lab of Wildlife Biotechnology, Conservation and Utilization of Zhejiang Province, Zhejiang \\ Normal University, Jinhua, Zhejiang, China \\ ${ }^{3}$ Department of Biology, Carleton University, Ottawa, ON, Canada \\ * These authors contributed equally to this work.
}

\section{ABSTRACT}

The owlflies (Family Ascalaphidae) belong to the Neuroptera but are often mistaken as dragonflies because of morphological characters. To date, only three mitochondrial genomes of Ascalaphidae, namely Libelloides macaronius; Ascaloptynx appendiculatus; Ascalohybris subjacens, are published in GenBank, meaning that they are greatly under-represented in comparison with the 430 described species reported in this family. In this study, we sequenced and described the complete mitochondrial genome of Suhpalacsa longialata (Neuroptera, Ascalaphidae). The total length of the $S$. longialata mitogenome was $15,911 \mathrm{bp}$, which is the longest known to date among the available family members of Ascalaphidae. However, the size of each gene was similar to the other three Ascalaphidae species. The $S$. longialata mitogenome included a transposition of tRNA $^{\text {Cys }}$ and tRNA ${ }^{\text {Trp }}$ genes and formed an unusual gene arrangement $\mathrm{tRNA}^{\mathrm{Cys}}$-tRNA ${ }^{\mathrm{Trp}}$-tRNA ${ }^{\text {Tyr }}$ (CWY). It is likely that the transposition occurred by a duplication of both genes followed by random loss of partial duplicated genes. The nucleotide composition of the $S$. longialata mitogenome was as follows: $A=41.0 \%, T=33.8 \%, C=15.5 \%, G=9.7 \%$. Both Bayesian inference and ML analyses strongly supported $S$. longialata as a sister clade to (Ascalohybris subjacens + L. macaronius), and indicated that Ascalaphidae is not monophyletic.

Subjects Entomology, Genomics, Molecular Biology

Keywords Neuroptera, Ascalaphidae, Mitochondrial genome, Phylogenetic relationship

\section{INTRODUCTION}

The study of mitochondrial genomes (mitogenomes) is of great interest to many scientific fields, including molecular evolution and evolutionary genomics (Avise et al., 1987; Salvato et al., 2008). Insect mitochondrial genomes are usually a double-stranded circular molecule with a length of $14-20 \mathrm{kbp}$, including 13 protein-coding genes (PCGs), 22 transfer RNAs (tRNAs), two ribosomal RNAs (rRNAs), and a control region (CR; AT-rich region) (Boore, 1999). The most widespread gene arrangement in insect mtDNAs is 
hypothesized to be ancestral for the entire Class Insecta (Clary \& Wolstenholme, 1985; Boore, Lavrov \& Brown, 1998; Cameron et al., 2006). However, more and more researchers have found other gene rearrangements in mitogenomes, mostly related to tRNAs or non-coding regions often within a selected family or order or these may even define clades at a variety of taxonomic scales below the ordinal level (Beard, Hamm \& Collins, 1993; Mitchell, Cockburn \& Seawright, 1993; Cameron \& Whiting, 2008; Salvato et al., 2008; McMahon, Hayward \& Kathirithamby, 2009; Cameron, 2014a). Consequently, the particular gene arrangement becomes a significant marker to delimit taxonomic boundaries. Furthermore, the mitogenome has been increasingly used to reconstruct phylogenetic relationships because of its simple genetic structure, maternal inheritance, and high evolutionary rate properties (Boyce, Zwick \& Aquadro, 1989; Sheffield et al., 2008; Jia \& Higgs, 2008; Du et al., 2017).

The insect Order Neuroptera contains approximately 6,000 species worldwide (Aspöck, 2002; Haring \& Aspöck, 2004). Known as net-winged insects, adults usually possess functional membranous wings with an extensive network of veins and cross-veins (Beckenbach \& Stewart, 2008). The fossil record of Neuroptera dates back to the Late Permian and indicates that they were a major group of insect fauna during the early diversification of the Holometabola (Aspöck, 2002). Therefore, their phylogenetic position is likely to have had a key influence on the subsequent evolution of insects (Beckenbach \& Stewart, 2008). To date, only 42 mitochondrial genomes of Neuroptera are available in databases (Beckenbach \& Stewart, 2008; Cameron et al., 2009; Haruyama et al., 2011; Negrisolo, Babbucci \& Patarnello, 2011; He et al., 2012; Zhao et al., 2013, 2016; Wang et al., 2013; Cheng et al., 2014, 2015; Yan et al., 2014; Zhang \& Wang, 2016; Lan et al., 2016; Zhang \& Yang, 2017; Song, Lin \& Zhao, 2018) and this includes 21 partial mitochondrial genomes. Hence, there is a great need to add data for more Neuroptera species in order to be able to analyze phylogenetic relationships both within this group and to further understand relationships within the Holometabola.

The owlflies (Family Ascalaphidae) belong to the Neuroptera but are often mistaken as dragonflies because of their morphological similarity. The larvae and adults of Ascalaphidae are usually predaceous and so they play an important role in maintaining ecological balance and pest control if they are well applied. At present, only three mitochondrial genomes of Ascalaphidae, namely Libelloides macaronius (Scopoli, 1763) (Negrisolo, Babbucci \& Patarnello, 2011); Ascaloptynx appendiculatus (Fabricius, 1793) (Beckenbach \& Stewart, 2008); Ascalohybris subjacens (Walker, 1853) (Cheng et al., 2014), are published in GenBank, meaning that they are greatly under-represented in comparison with the 430 described species reported in this family (Stange, 2004). These three published genomes show substantial gene rearrangements in contrast to those of the assumed ancestral insects (Beckenbach \& Stewart, 2008; Negrisolo, Babbucci \& Patarnello, 2011; Cheng et al., 2014) and it is unclear if the mitogenome of any of these species represents the common condition within the Ascalaphidae. The monophyly of Ascalaphidae was supported by Wang et al. (2017) and Song, Lin \& Zhao (2018), while the monophyly of Myrmeleontidae did not recovered by Wang et al. (2017) because the monophyly of Ascalaphidae clustered into the clade of Myrmeleontidae. Increasing 
the number of sequenced species within the Neuroptera will be very helpful for phylogenetic reconstructions of Neuroptera relationships. Hence, in the present study we sequenced the complete mitogenome of Suhpalacsa longialata Yang 1992 (Neuroptera, Ascalaphidae) and analyzed its genomic structure and composition in comparison with the other three Ascalaphidae species including determining nucleotide composition, gene order, codon usage, and secondary structure of tRNAs. Additionally, we also analyzed evolutionary relationships within Neuroptera using Megaloptera as outgroups to discuss the relationship between Ascalaphidae and Myrmeleontidae, and the relationships of inter-families of Neuroptera.

\section{MATERIALS AND METHODS}

\section{Sample origin and DNA extraction}

The sample of an adult $S$. longialata used for sequencing was collected from Hangzhou, Zhejiang province, China in July 2017 by LP Zhang. The specimen was identified by JY Zhang and preserved in $100 \%$ ethanol at $-40{ }^{\circ} \mathrm{C}$ in the lab of JY Zhang. Total DNA was isolated from one foreleg of S. longialata using Ezup Column Animal Genomic DNA Purification Kit (Sangon Biotech Company, Shanghai, China) according to the manufacturer's protocol.

\section{PCR amplification and sequencing of $S$. longialata mtDNA}

A total of 12 universal primers for polymerase chain reaction (PCR) amplification were modified according to Simon et al. (2006), Zhang et al. (2008), and Zhang et al. (2018) (Table S1; Fig. 1) based on the mitogenome sequences of the three-known species of Ascalaphidae (L. macaronius, Ascaloptynx appendiculatus, and Ascalohybris subjacens). Then five specific primers (Table S1; Fig. 1) were designed based on the sequence information from universal primers using Primer Premier 5.0 (PREMIER Biosoft International, CA, USA). All PCR was performed with a BioRADMJMini Personal Thermal Cycler (made in Singapore) using Takara Taq DNA polymerase (TaKaRa Biotechnology Co., Ltd., Dalian, China) with the following cycling steps: denaturation at $94{ }^{\circ} \mathrm{C}$ for $5 \mathrm{~min}$, followed by 35 cycles of $94{ }^{\circ} \mathrm{C}$ (50 s for denaturation), $48-60{ }^{\circ} \mathrm{C}(30-50 \mathrm{~s}$ for annealing), and $72{ }^{\circ} \mathrm{C}\left(1-3\right.$ min elongation), followed by a final elongation at $72{ }^{\circ} \mathrm{C}$ for $10 \mathrm{~min}$. PCR reactions were carried out in a $50 \mu \mathrm{L}$ reaction volume consisting of $32.75 \mu \mathrm{L}$ sterile deionized water, $5.0 \mu \mathrm{L} 10 \times$ PCR buffer $\left(\mathrm{Mg}^{2+}\right.$ Free $), 5.0 \mu \mathrm{L} \mathrm{MgCl}_{2}$ (25 mM), $4.0 \mu \mathrm{L}$ dNTP Mixture (2.5 mM each), 1.0 $\mu \mathrm{L}$ DNA template, $1.0 \mu \mathrm{L}$ each primer $(10 \mathrm{ppm}), 0.25 \mu \mathrm{L}$ Takara Taq DNA polymerase $(5 \mathrm{U} / \mu \mathrm{L})$. All PCR products were visualized by electrophoresis in a $1 \%$ agarose gel and sent to Sangon Biotech Company (Shanghai, China) for sequencing of both strands.

\section{Mitogenome annotation and sequence analyses}

The mtDNA sequence was assembled using DNASTAR Package v.6.0 (Burland, 2000). The tRNA genes and their cloverleaf secondary structures were determined by MITOS (Bernt et al., 2013, available at http://mitos.bioinf.uni-leipzig.de/index.py) using the invertebrate mitogenome genetic code. The CR and rRNA genes were identified by the 


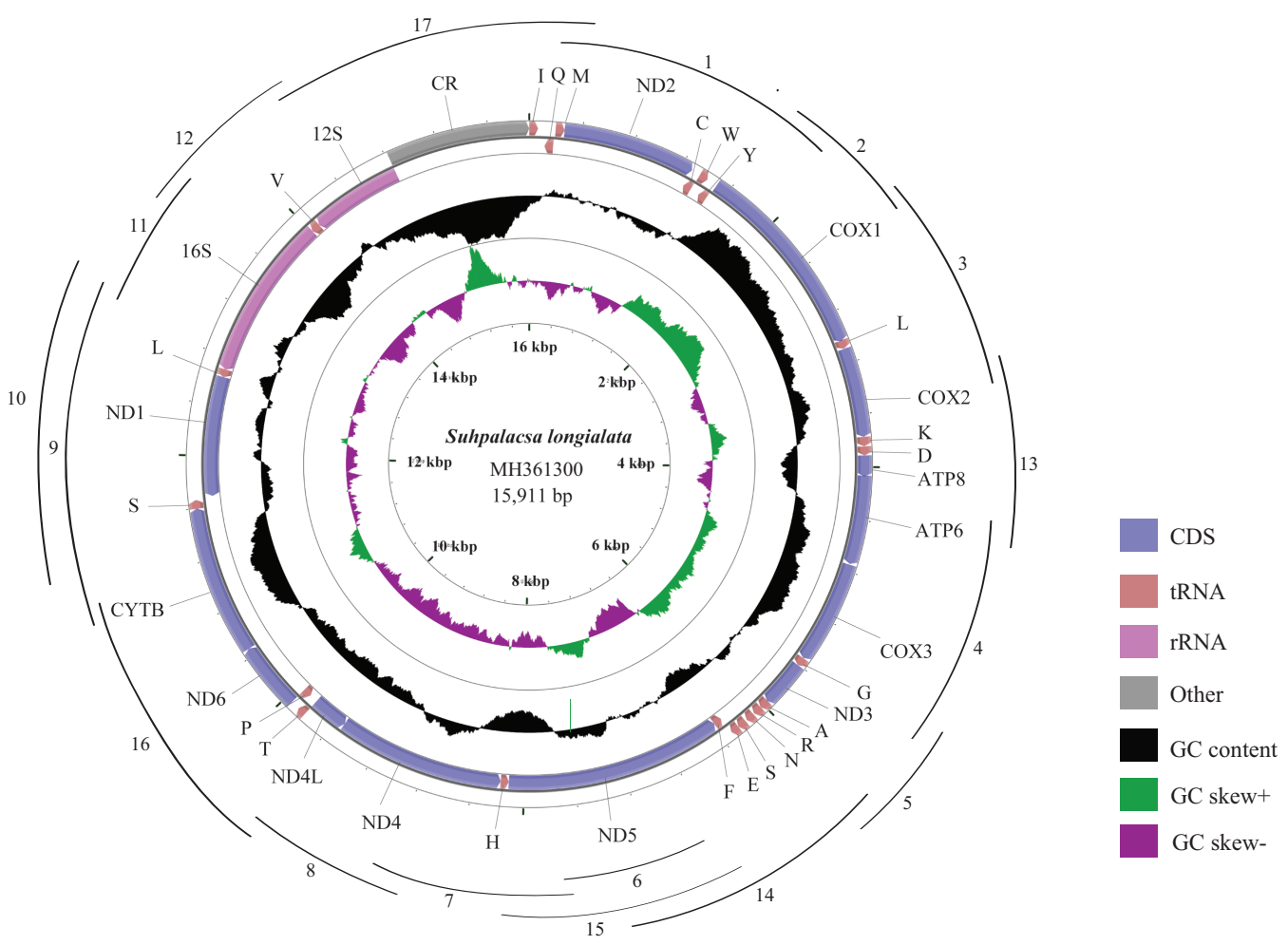

Figure 1 Mitogenome map of S. longialata. The outermost circle shows the gene map of S. longialata and the genes outside the map are coded on the major strand (J-strand), whereas the genes on the inside of the map are coded on the minor strand (N-strand). The middle circle (black) displays the GC content and the paracentral circle (purple \& green) displays the GC skew. Both GC content and GC skew are plotted as the deviation from the average value of the total sequence. A total of 17 arcs display the PCR amplification methods. All primers are shown in Table S1.

Full-size 0 DOI: 10.7717/peerj.5914/fig-1

boundary of tRNA genes (Thompson et al., 1997) as well as comparison with homologous sequences of mitogenomes from other species of Ascalaphidae (Beckenbach \& Stewart, 2008; Negrisolo, Babbucci \& Patarnello, 2011; Cheng et al., 2014). The 13 PCGs were translated to amino acids with the invertebrate mitogenome genetic code and the open reading frames were identified using Mega 7.0 (Kumar, Stecher \& Tamura, 2016; Cameron, 2014b). The nucleotide composition, codon usage, and relative synonymous codon usage (RSCU) were calculated by Mega 7.0 (Kumar, Stecher \& Tamura, 2016). The GC and AT skews were calculated using the following formulae: AT skew $=(A-T) /(A+T)$, GC skew $=(G-C) /(G+C)($ Perna \& Kocher, 1995). A mitogenome map of S. longialata was constructed using CG View server V 1.0 (Grant \& Stothard, 2008).

\section{Phylogenetic analyses}

For Megaloptera as a sister clade to Neuroptera proposed by Engel, Winterton \& Breitkreuz (2018) and Peters et al. (2014), four species of Megaloptera (Corydalus cornutus; Dysmicohermes ingens; Neochauliodes bowringi; Sialis hamata) (Beckenbach \& Stewart, 2008; Cameron et al., 2009; Li et al., 2015; Wang, Liu \& Yang, 2016) were used to as 
outgroups in phylogenetic analyses. We downloaded the data from previously sequenced species of Neuroptera as ingroups including S. longialata (Beckenbach \& Stewart, 2008; Cameron et al., 2009; Cheng et al., 2014, 2015; Haruyama et al., 2011; He et al., 2012; Jiang et al., 2017; Lan et al., 2016; Negrisolo, Babbucci \& Patarnello, 2011; Wang et al., 2012, 2013, 2017; Yan et al., 2014; Zhao et al., 2013, 2016; Zhang \& Wang, 2016; Zhang \& Yang, 2017) to discuss family-level phylogenetic relationships of Neuroptera. Accession numbers of all mitochondrial genomes are listed in Table S2. Nucleotide sequences of the 13 PCGs were employed for construction of Bayesian inference (BI) and maximum likelihood (ML) phylogenetic trees according to Cheng et al. (2016) and Zhang et al. (2018). DNA alignment was acquired from the amino acid alignment of the 13 PCGs using Clustal W in Mega 7.0 (Kumar, Stecher \& Tamura, 2016), and the conserved regions were found by Gblock 0.91b (Castresana, 2000). We estimated the best partitioning scheme and model by the program PartionFinder 1.1.1 (Lanfear et al., 2012) on the basis of Bayesian information criterion. The ML tree was constructed in RAxML 8.2.0 with the best

model of GTRGAMMA and the branch support inferred from 1,000 bootstrap replications (Stamatakis, 2014). BI analysis was carried out in MrBayes 3.2 (Ronquist et al., 2012) with the model of GTR + I + G; the analysis was set for 10 million generations with sampling every 1,000 generations; the initial $25 \%$ of generations was discarded as burn-in. Because long branch attraction (LBA) can cause a wrong relationship (Bergsten, 2005; Philippe et al., 2005), we obtained a second data set using 40 species of Neuroptera (40SN) as the ingroup by excluding Semidalis aleyrodiformis, Coniopteryx sp., and Dilar sp. that showed LBA. The ML and the BI analyses of data 40SN were then performed as above.

\section{RESULTS AND DISCUSSION}

\section{Mitogenome organization and structure}

The complete mitogenome of $S$. longialata is a double-stranded circular DNA molecule with a length of 15,911 bp (Fig. 1) that has been submitted to GenBank under the accession number MH361300. It encodes the entire set of 37 mitochondrial genes including 13 PCGs, 22 tRNA genes, and two rRNA genes that are typically present in metazoan mitogenomes (Wolstenholme, 1992). In addition, the gene arrangement of S. longialata is similar to the assumed common ancestor of insects (Mueller \& Boore, 2005; Yu et al., 2007; Erler et al., 2010; Li et al., 2011, 2012a, 2012b), with the exception of the tRNA ${ }^{\text {Trp }}$-tRNA ${ }^{\text {Cys }}$-tRNA ${ }^{\text {Tyr }}$ (WCY) triplet. S. longialata possessed an unusual gene order of tRNA ${ }^{\text {Cys }}$-tRNA ${ }^{\text {Trp }}$-tRNA ${ }^{\text {Tyr }}$ (CWY) (Fig. 1), which also occurred in the other species of Ascalaphidae available in the GenBank database (Beckenbach \& Stewart, 2008; Negrisolo, Babbucci \& Patarnello, 2011; Cheng et al., 2014). In addition, the transposition of tRNA ${ }^{\text {Cys }}$ and $\mathrm{tRNA}^{\mathrm{Trp}}$ genes has also been found in other families within the Neuroptera, including Dilaridae, Hemerobiidae, Mantispidae, Berothidae, Ithonidae, Chrysopidae, Psychopsidae, Nymphidae, Nemopteridae, and Myrmeleontidae (Wang et al., 2017; Song, Lin \& Zhao, 2018), but not in the other neuropterid orders. Thus, it is widely acknowledged that it may be synapomorphic for the Neuroptera (Cameron et al., 2009; Beckenbach \& Stewart, 2008; Haruyama et al., 2011; Negrisolo, Babbucci \& Patarnello, 2011; He et al., 2012; Zhao et al., 2013; Yan et al., 2014). 
Table 1 Base composition of the mitochondrial genomes of four species of Ascalaphidae.

\begin{tabular}{|c|c|c|c|c|c|c|c|c|c|c|c|c|c|c|c|c|}
\hline \multirow[t]{2}{*}{ Region } & \multicolumn{4}{|c|}{ S. longialata } & \multicolumn{4}{|c|}{ L. macaronius } & \multicolumn{4}{|c|}{ A. appendiculatus } & \multicolumn{4}{|c|}{ A. subjacens } \\
\hline & $\begin{array}{l}\text { Length } \\
\text { (bp) }\end{array}$ & AT\% & $\begin{array}{l}\text { AT- } \\
\text { skew }\end{array}$ & $\begin{array}{l}\text { GC- } \\
\text { skew }\end{array}$ & $\begin{array}{l}\text { Length } \\
\text { (bp) }\end{array}$ & $\mathrm{AT} \%$ & $\begin{array}{l}\text { AT- } \\
\text { skew }\end{array}$ & $\begin{array}{l}\text { GC- } \\
\text { skew }\end{array}$ & $\begin{array}{l}\text { Length } \\
\text { (bp) }\end{array}$ & AT\% & $\begin{array}{l}\text { AT- } \\
\text { skew }\end{array}$ & $\begin{array}{l}\text { GC- } \\
\text { skew }\end{array}$ & $\begin{array}{l}\text { Length } \\
\text { (bp) }\end{array}$ & AT\% & $\begin{array}{l}\text { AT- } \\
\text { skew }\end{array}$ & $\begin{array}{l}\text { GC- } \\
\text { skew }\end{array}$ \\
\hline $\begin{array}{l}\text { Whole } \\
\text { genome }\end{array}$ & 1,5911 & 74.8 & 0.096 & -0.230 & 15,890 & 74.5 & 0.071 & -0.176 & 15,877 & 75.5 & 0.068 & -0.205 & 15,873 & 75.7 & 0.054 & -0.177 \\
\hline $\begin{array}{l}\text { Protein- } \\
\text { coding } \\
\text { genes }\end{array}$ & 11,169 & 73.0 & 0.090 & -0.234 & 11,181 & 73.1 & 0.078 & -0.182 & 11,169 & 74.0 & 0.059 & -0.338 & 11,183 & 74.1 & 0.050 & -0.169 \\
\hline $\begin{array}{l}\text { Ribosomal } \\
\text { RNA } \\
\text { genes }\end{array}$ & 2,053 & 77.8 & 0.159 & -0.297 & 2,095 & 76.4 & 0.094 & -0.241 & 2,078 & 78.6 & 0.125 & -0.280 & 2,094 & 77.8 & 0.108 & -0.270 \\
\hline $\begin{array}{c}\text { Transfer } \\
\text { RNA } \\
\text { genes }\end{array}$ & 1,476 & 76.2 & 0.055 & -0.122 & 1,471 & 75.6 & 0.037 & -0.115 & 1,464 & 75.5 & 0.057 & -0.135 & 1,466 & 77.7 & 0.037 & -0.135 \\
\hline $\begin{array}{c}A+T \text {-rich } \\
\text { region }\end{array}$ & 1,088 & 85.1 & 0.086 & -0.168 & 1,049 & 84.5 & 0.030 & 0.006 & 1,066 & 85.7 & 0.048 & -0.077 & 1,051 & 86.2 & 0.035 & -0.014 \\
\hline
\end{tabular}

The duplication-random loss model may be a possible explanation for the transposition of contiguous genes. Similar to the report by Beckenbach \& Stewart (2008), it is likely that the tRNA ${ }^{\text {Trp }}$-tRNA ${ }^{\text {Cys }}$ (WC) genes were duplicated in tandem to form a tRNA cluster WCWC, which was then followed by random loss of partial duplicated genes to produce the final CW gene order.

The mitogenome of $S$. longialata $(15,911 \mathrm{bp})$ is the longest as compared with those of other Ascalaphidae species, whose mitogenomes range from 15,873 to 15,890 bp. The greater length of the $S$. longialata mitogenome is due largely to 16 intergenic regions ranging from 1 to $54 \mathrm{bp}$ and a long typical $A+T$-rich region (1,088 bp) as compared to 1,049 bp for L. macaronius (Negrisolo, Babbucci \& Patarnello, 2011), 1,066 bp for Ascaloptynx appendiculatus (Beckenbach \& Stewart, 2008), and 1,051 bp for Ascalohybris subjacens (Cheng et al., 2014). The nucleotide composition of the S. longialata mitogenome is as follows: $A=41.0 \%, T=33.8 \%, C=15.5 \%, G=9.7 \%$. It is obvious that the S. longialata had a strong $A+T$ bias of $74.8 \%$, which is similar to other species of the Ascalaphidae: $74.5 \%$ for L. macaronius; $75.5 \%$ for Ascaloptynx appendiculatus; $75.7 \%$ for Ascalohybris subjacens (Beckenbach \& Stewart, 2008; Negrisolo, Babbucci \& Patarnello, 2011; Cheng et al., 2014) (Table 1). The high $A+T$ bias was found in PCGs, rRNA genes, tRNA genes, and the CR. Previous studies pointed out that the strand bias in nucleotide composition may be attributed to mutational damage primarily affecting the lagging strand during asymmetric replication (Francino \& Ochman, 1997; Hassanin, Leger \& Deutsch, 2005). The skew statistics indicated that S. longialata had a positive AT-skew and negative GC-skew (Table 1).

\section{Protein-coding genes and codon usages}

Nine PCGs (ND2, COX1, COX2, ATP8, ATP6, COX3, ND3, ND6, and CYTB) were located on the major strand (J-strand) with the remaining PCGs on the minor strand 


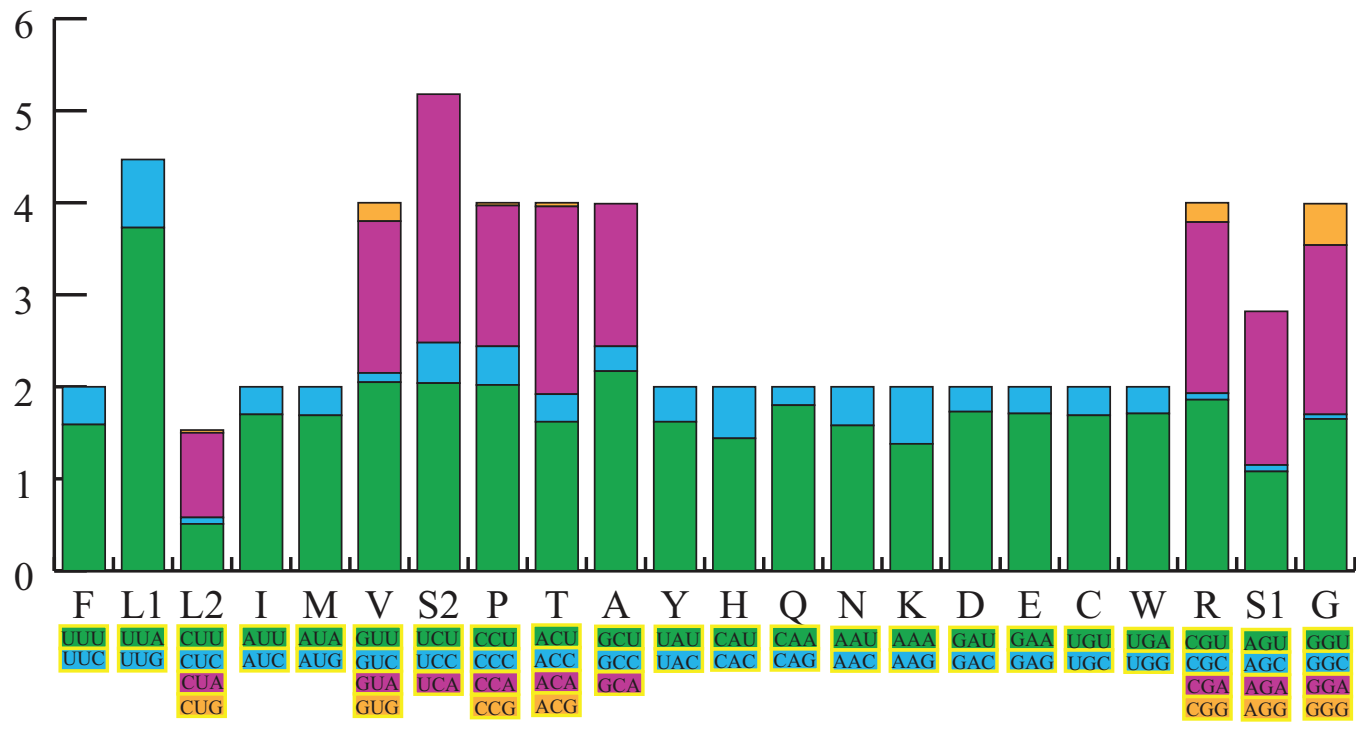

Figure 2 The relative synonymous codon usage (RSCU) in the S. longialata mitogenome. Codon families are provided on the $x$-axis along with the different combinations of synonymous codons that code for that amino acid. RSCU are provided on the $y$-axis. Full-size $\underline{0}$ DOI: 10.7717/peerj.5914/fig-2

(N-strand). All PCGs genes used ATN ( $N$ represents $A, G, C$, or $T$ ) as initiation codons, which have been accepted as the canonical mitochondrial start codons for insect mitogenomes (Wolstenholme, 1992). Termination codons for S. longialata were mostly complete (TAA) with some incomplete (TA or T). Such incomplete stop codons have been found in various insect species (Ma et al., 2015; Nardi et al., 2001; Fenn, Cameron \& Whiting, 2007), and it has been determined that incomplete stop codons can produce functional stop codons in polycistronic transcription cleavage and polyadenylation processes (Ojala, Montoya \& Attardi, 1981). The only exception was detected in ND1, where S. longialata exhibited TAG as the stop codon. The infrequent use of TAG may be because of the high $A+T$ composition of the PCGs, although TAG is the conservative stop codon in most insect mitogenomes (Liu et al., 2015). However, in the other three published Ascalaphidae mitogenomes, COX1 of L. macaronius (Negrisolo, Babbucci \& Patarnello, 2011), Ascaloptynx appendiculatus (Beckenbach \& Stewart, 2008), and Ascalohybris subjacens (Cheng et al., 2014) used ACG as the start codons, and ND1 of Ascalohybris subjacens used TTG. The other start/stop codons were identical to the S. longialata situation.

The total length of the 13 PCGs in the $S$. longialata mitogenome was 11,169 bp, with an average AT content of $73.0 \%$. The PCGs displayed $A$-skews $(A>T)$ and $C$-skews $(C>G$ ) (Table 1$)$. We calculated the RSCU of the $S$. longialata mitogenome, excluding stop codons (Fig. 2). The RSCU proved that codons with $A$ or $T$ in the third position are always overused when compared to the other synonymous codons. The codons of amino acids being NNW (NNA/NNU) were higher than 1.0 without exception in S. longialata. The most frequently encoded amino acids were Leu (UUR), Phe, Ile $(>300)$, and the least frequently used amino acid was Cys $(<45)$ (Table S3), which was similar to the other Ascalaphidae mitogenomes (Fig. 2). 


\section{Ribosomal and transfer RNAs}

The mtDNA of $S$. longialata contained the entire content of 2 rRNAs and 22 tRNAs genes that were also found in other neuropterid mitogenomes (Boore, 1999; Song, Lin \& Zhao, 2018; Wang et al., 2017). The 16S rRNA gene with a length of 1,314 bp was located between $\mathrm{tRNA}^{\mathrm{Leu}}(\mathrm{CUN})$ and $\mathrm{tRNA}{ }^{\mathrm{Val}}$ whereas the $12 \mathrm{~S}$ rRNA gene with a size of $739 \mathrm{bp}$ was located between tRNA ${ }^{\mathrm{Val}}$ and the CR; these locations were also detected in the other ascalaphid owlfly species (Beckenbach \& Stewart, 2008; Negrisolo, Babbucci \& Patarnello, 2011; Cheng et al., 2014). The AT content of rRNAs in the S. longialata mitogenome was the highest (77.8\%) except for the $A+T$-rich region (85.1\%). We found that the AT-skew was strongly positive whereas the GC-skew was highly negative, which showed that the contents of $A$ and $C$ were higher than those of $T$ and $G$, respectively.

The size of the tRNAs was $1,476 \mathrm{bp}$ with an average $A+T$ content of $76.2 \%$. Among the 22 tRNAs, most tRNA genes displayed the common cloverleaf secondary structure, whereas the tRNA ${ }^{\text {Ser(AGN) }}$ had lost the dihydrouridine (DHU) arm (Fig. 3). The absence of this arm in tRNA ${ }^{\mathrm{Ser}(\mathrm{AGN})}$ is a typical feature of many insect mtDNAs (Wolstenholme, 1992; Salvato et al., 2008; Sheffield et al., 2008; Negrisolo, Babbucci \& Patarnello, 2011; Yan et al., 2014; Du et al., 2017; Zhang, Song \& Zhou, 2008), and is usually demonstrated to be functional (Hanada et al., 2001; Stewart \& Beckenbach, 2003). We also found that the tRNA ${ }^{\text {Phe }}$ and tRNA ${ }^{\text {Leu }(C U N)}$ lack the T $\psi C$ loops. Furthermore, unmatched U-U base pairs were observed in $\mathrm{tRNA}^{\mathrm{Trp}}$ (Fig. 3).

In terms of the tRNA gene structures of the other three ascalaphid owlflies, the tRNA ${ }^{\text {Phe }}$ in L. macaronius and Ascalohybris subjacens showed the loss of T $\psi \mathrm{C}$ loops, and the tRNA $^{\text {Ser (AGN) }}$ in Ascalohybris subjacens lost the DHU loop, whereas the tRNA genes of Ascaloptynx appendiculatus displayed the typical cloverleaf secondary structure.

\section{$A+T$-rich region and intergenic regions}

Generally speaking, the $A+T$-rich region was the largest non-coding region, which was located between $12 \mathrm{~S}$ rRNA and tRNA ${ }^{\text {Ile }}$. The $A+T$-rich region of $S$. longialata mtDNA having a length of $1,088 \mathrm{bp}$ was the longest when compared to the other three species of Ascalaphidae, for example, the L. macaronius (1,049 bp), Ascaloptynx appendiculatus $(1,066)$, and Ascalohybris subjacens (1,051 bp). Additionally, the composition of $A+T$ was $85.1 \%$ in S. longialata, which was higher than in L. macaronius (84.5\%) and lower than Ascaloptynx appendiculatus (85.7\%) and Ascalohybris subjacens (86.2\%).

The mitochondrial genomes of most insects are compact (Boore, 1999), although large intergenic regions occur in some species. In the $S$. longialata mitogenome the longest intergenic region was a 54 bp insertion between $\mathrm{tRNA}^{\text {Ile }}$ and tRNA ${ }^{\text {Gln }}$. This spacer was also present in L. macaronius, Ascaloptynx appendiculatus, and Ascalohybris subjacens and spanned 55, 42, 54 bp, respectively (Beckenbach \& Stewart, 2008; Negrisolo, Babbucci \& Patarnello, 2011; Cheng et al., 2014). This intergenic region of the four species also shared a 12 bp long congruent motif $A(A / G) T T A A(A / C) T A A A T$ adjacent to tRNA ${ }^{\text {Gln }}$. It has previously been reported that this spacer may diverge quickly among different families of the same order (Negrisolo, Babbucci \& Patarnello, 2011). Aside from this spacer, gaps between genes ranged from 1 to 18 residues in the $S$. longialata sequence. 

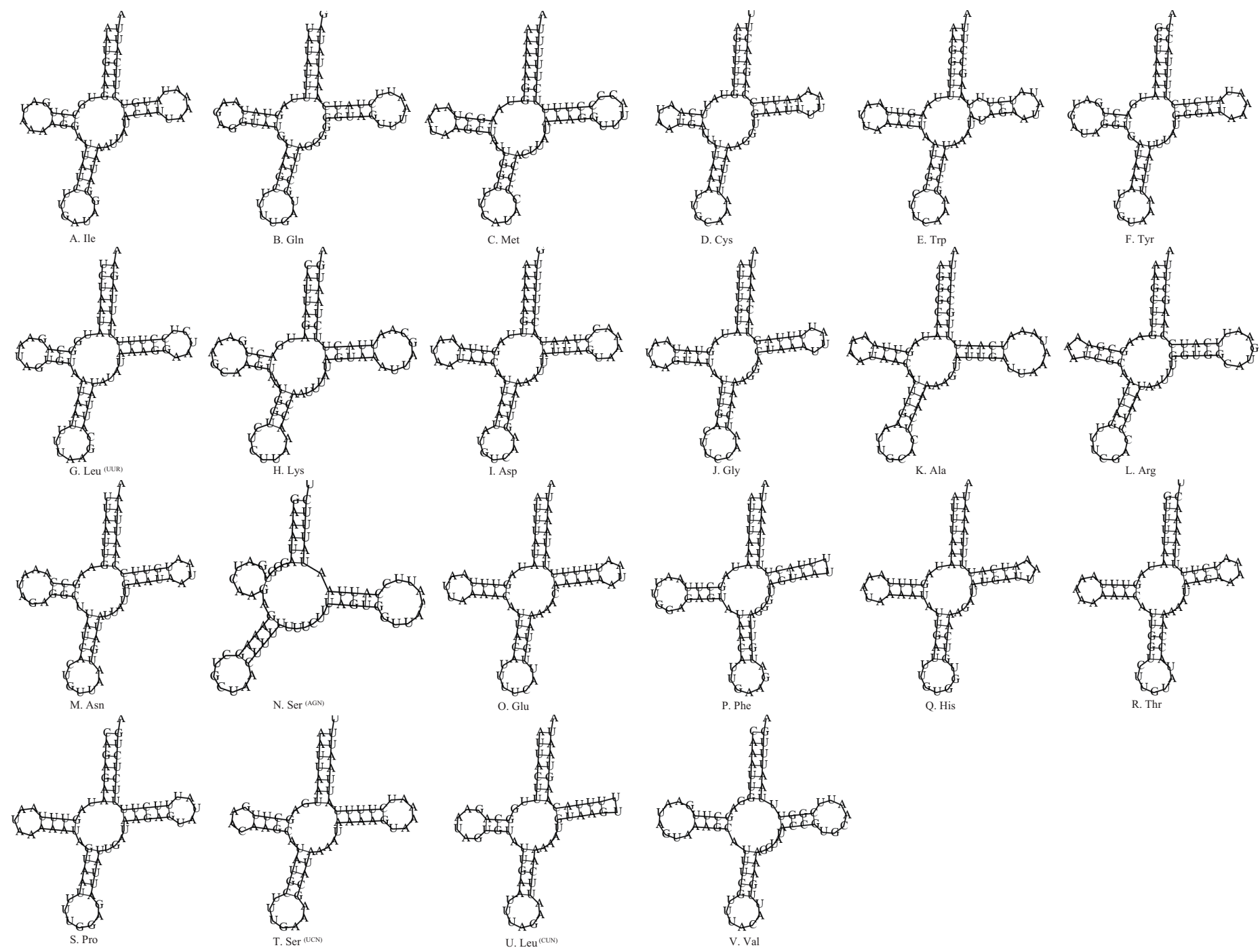

Figure 3 Secondary structures for 22 transfer RNAs in the $\boldsymbol{S}$. longialata mitogenome. (A) Ile, (B) Gln, (C) Met, (D) Cys, (E) Trp, (F) Tyr, (G) Leu, (H) Lys, (I) Asp, (J) Gly, (K) Ala, (L) Arg, (M) Asn, (N) Ser, (O) Glu, (P) Phe, (Q) His, (R) Thr, (S) Pro, (T) Ser, (U) Leu, (V) Val.

Full-size iص DOI: 10.7717 /peerj.5914/fig-3

\section{Phylogenetic analyses}

The phylogenetic relationships including the long-branch attraction species deduced from BI analysis and ML analysis are shown in Fig. 4, and they present somewhat different topologies. In the ML analysis, Hemerobiidae is a sister clade to (Berothidae + Mantispidae) with low support (ML 29). However, in the BI analysis Hemerobiidae is a sister clade to Chrysopidae with high support (BI 1) (Fig. 4). The high support found for both relations (Hemerobiidae + Chrysopidae) and ((Hemerobiidae + Chrysopidae) + (Berothidae + Mantispidae)) only in the BI analysis. In the ML analysis (Sisyra nigra + Climacia areolaris) is a clade sister to (Nevrorthus apatelios + Nipponeurorthus fuscinervis), but in BI (Sisyra nigra + Climacia areolaris) is a clade sister to (Coniopteryx sp. + Semidalis aleyrodiformis). It has been demonstrated that the LBA artefact will affect both ML and BI tree reconstruction methods (Huelsenbeck \& Hillis, 1993; Huelsenbeck, 1995; 


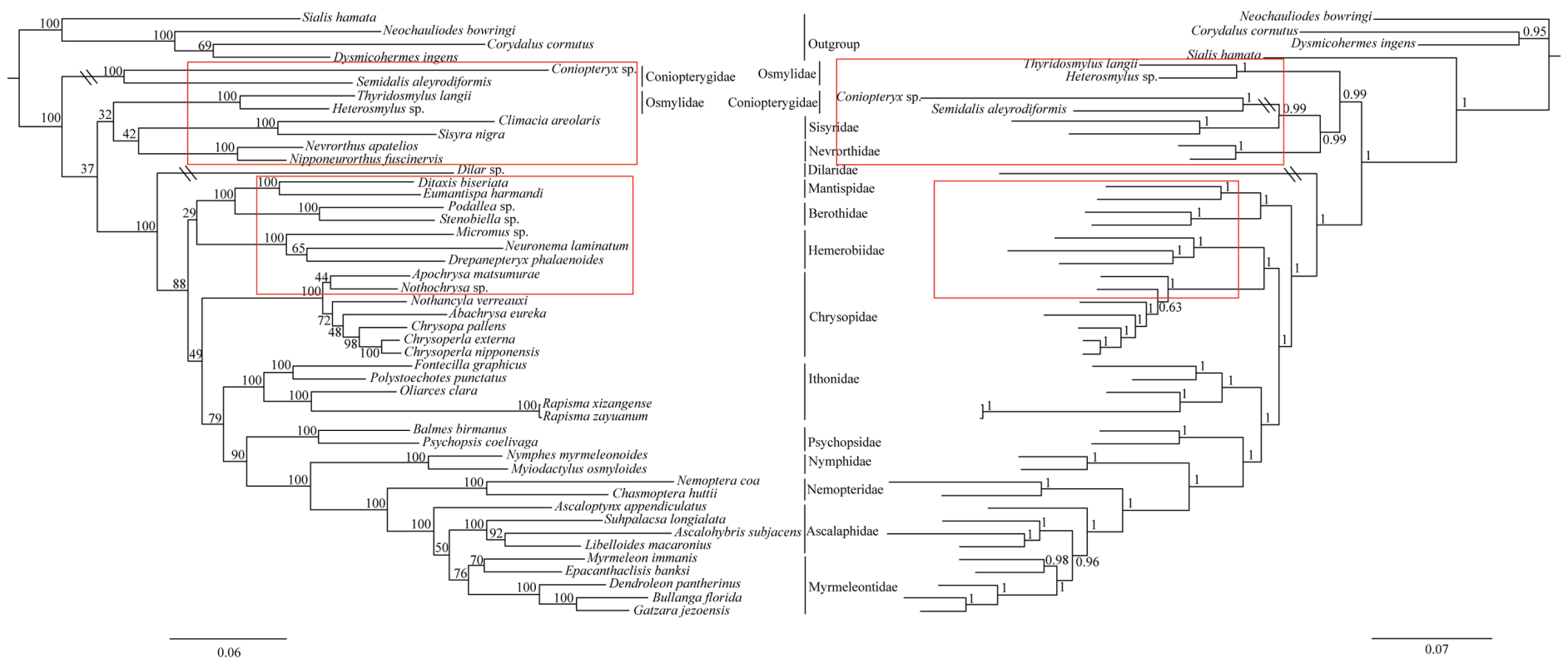

Figure 4 Phylogenetic relationships of Neuroptera in ML and BI analyses. The data is includes 43 species of Neuroptera as the ingroup and four species of Megaloptera as the outgroup. The red boxes on the figure mean different topology.

Full-size i DOI: $10.7717 /$ peerj.5914/fig-4
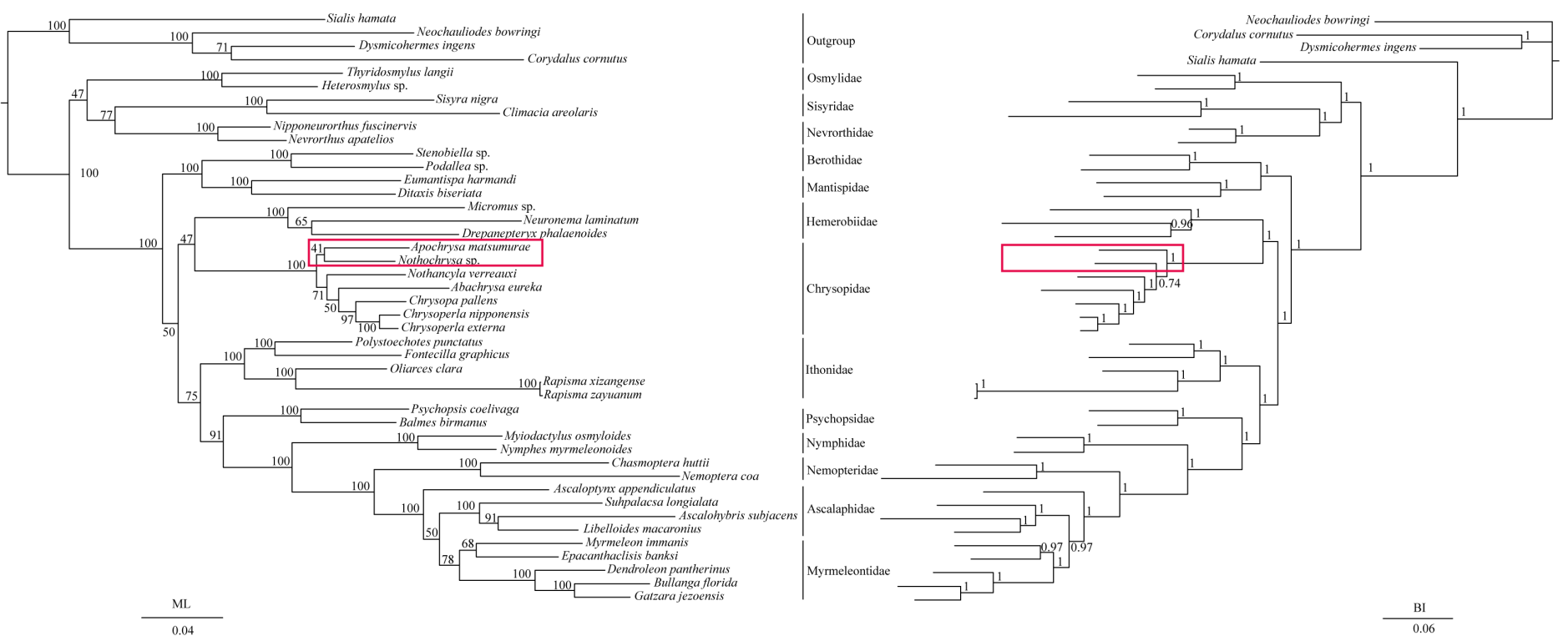

Figure 5 Phylogenetic relationships of Neuroptera in ML and BI analyses after the elimination of three species (Semidalis aleyrodiformis, Coniopteryx sp., Dilar sp.). The data include 40 species of Neuroptera as the ingroup and four species of Megaloptera as the outgroup. The red boxes on the figure mean different topology. Full-size 0 DOI: 10.7717 /peerj.5914/fig-5

Philippe, 2000; Philippe et al., 2005). Thus, we propose that the difference between the ML and BI analyses were caused mainly by LBA of Coniopteryx sp., Dilar sp., and Semidalis aleyrodiformis. According to Bergsten (2005), a method excluding long branch taxa can avoid LBA. So we removed three species (Semidalis aleyrodiformis, Coniopteryx sp., Dilar sp.) and reconstructed the phylogeny of Neuroptera (Fig. 5). In this situation, taking 
no account of the outgroup, both the ML and BI phylogenetic trees showed identical topologies and high support values for most clades, except for the internal relations within the family Chrysopidae. Apochrysa matsumurae is a sister clade to Nothochrysa sp. and then (Apochrysa matsumurae + Nothochrysa sp.) is a sister clade of (Nothancyla verreauxi $+($ Abachrysa eureka $+($ Chrysopa pallens + (Chrysoperla nipponensis + Chrysoperla externa)))) in ML analysis, whereas in BI analysis (Apochrysa matsumurae + (Nothochrysa sp. $+($ Nothancyla verreauxi $+($ Abachrysa eureka $+($ Chrysopa pallens + (Chrysoperla nipponensis + Chrysoperla externa)))))) (Fig. 5). On the whole, this analysis recovers the monophyly of all Neuroptera families except the Ascalaphidae, previously reported as monophyletic by Wang et al. (2017) and Song, Lin \& Zhao (2018). Two clades of Neuroptera are recovered: one clade is (Osmylidae + (Sisyridae + Nevrorthidae)) and the other clade is (Berothidae + Mantispidae $)+(($ Hemerobiidae + Chrysopidae $)+$ (Ithonidae $+(($ Psychopsidae + (Nymphidae $+(($ Nemopteridae $+($ Ascaloptynx appendiculatus of Ascalaphidae + (Ascalaphidae + Myrmeleontidae) $)))))))$ ). In the ML analysis LBA existed with all families of Neuroptera (Fig. 4) and Coniopterygidae is recovered as sister clade to the remaining extant Neuroptera, which is consistent with the conclusions of Wang et al. (2017) and Winterton, Hardy \& Wiegmann (2010), Winterton et al. (2018). By contrast, in the BI analysis (Fig. 4) Osmylidae is recovered as sister clade to (Coniopterygidae $+($ Sisyridae + Nevrorthidae $)$ ). These difference may be caused by the model selection. In this study, we also found that the clade of (Nevrorthidae + Sisyridae) is sister clade of Osmylidae and the clade of ((Nevrorthidae + Sisyridae) + Osmylidae) is sister clade of other extant Neuroptera, excluding Coniopterygidae (Fig. 5), which was also found by Wang et al. (2017) and Winterton, Hardy \& Wiegmann (2010). The sister relationship of Myrmeleontidae and Ascalaphidae is supported by Song, Lin \& Zhao (2018). Myrmeleontidae is monophyletic and Ascalaphidae is not monophyletic in this study. In addition, we make further discussions on the unclear relationship between/within Myrmeleontidae and Ascalaphidae, which were previously controversial since the recent results of mitogenomic phylogeny do not support the monophyly of Myrmeleontidae or Ascalaphidae. (Yan et al., 2014; Lan et al., 2016; Winterton et al., 2018; Zhao, Zhang \& Zhang, 2017). In this study, the topology is as follows: ((Myrmeleon immanis + Epacanthaclisis banksi $)+($ Dendroleon pantherinus $+($ Bullanga florida + Gatzara jezoensis))) (ML 78, BI 1) (Fig. 5), which supports the monophyly of Myrmeleontidae. Among them, the S. longialata that we sequenced is a sister clade to (Ascalohybris subjacens + L. macaronius), which showed high support both in ML and BI analysis. Because of the increase in species of Neuroptera included in the present analysis, the topologies of the phylogenetic relationships were somewhat different to those of Wang et al. (2017) who reported that Myrmeleon immanis is a sister clade to (Dendroleon pantherinus + (Ascaloptynx appendiculatus + (L. macaronius + Ascalohybris subjacens))). However in present study showed the topology as follows: (Ascaloptynx appendiculatus $+(($ S. longialata $+($ Ascalohybris subjacens + L. macaronius $))+$ the clade Myrmeleontidae)). We found with the inclusion of $S$. longialata that the monophyly of Ascalaphidae was recovered by Wang et al. (2017) and Song, Lin \& Zhao (2018) did not recover in our results. The monophyly of Ascalaphidae and Myrmeleontidae will need 
more species to be added before they can be discussed further. Consequently, we believe that increasing the abundance of mitochondrial genomes of Neuroptera will make a significant difference to resolving and reconstructing the phylogenetic relationships within Neuroptera.

\section{CONCLUSION}

We successfully sequenced the entire mitochondrial genome of $S$. longialata, which showed similar gene characteristics to the other three species of Ascalaphidae. Both BI and ML analyses supported S. longialata as a clade sister to (Ascalohybris subjacens + L. macaronius), but Ascalaphidae is not monophyletic. From the results obtained in the present study, we believe the different topologies of phylogenetic relationships were caused mainly by LBA of Coniopteryx sp., Dilar sp., and Semidalis aleyrodiformis.

\section{ACKNOWLEDGEMENT}

We thank Le-Ping Zhang for help in sample collection.

\section{ADDITIONAL INFORMATION AND DECLARATIONS}

\section{Funding}

This research was supported by the Zhejiang provincial Natural Science Foundation (Y18C040006) and the National Natural Science Foundation of China (31370042).

The funders had no role in study design, data collection and analysis, decision to publish, or preparation of the manuscript.

\section{Grant Disclosures}

The following grant information was disclosed by the authors:

Zhejiang provincial Natural Science Foundation: Y18C040006.

National Natural Science Foundation of China: 31370042.

\section{Competing Interests}

Kenneth B. Storey is an Academic Editor for PeerJ.

\section{Author Contributions}

- Xin-Yan Gao performed the experiments, analyzed the data, prepared figures and/or tables, authored or reviewed drafts of the paper.

- Yin-Yin Cai performed the experiments, analyzed the data, prepared figures and/or tables, authored or reviewed drafts of the paper.

- Dan-Na Yu conceived and designed the experiments, analyzed the data, prepared figures and/or tables, authored or reviewed drafts of the paper.

- Kenneth B. Storey prepared figures and/or tables, authored or reviewed drafts of the paper.

- Jia-Yong Zhang conceived and designed the experiments, analyzed the data, contributed reagents/materials/analysis tools, prepared figures and/or tables, authored or reviewed drafts of the paper, approved the final draft. 


\section{Data Availability}

The following information was supplied regarding data availability:

GenBank number: MH361300.

\section{Supplemental Information}

Supplemental information for this article can be found online at http://dx.doi.org/10.7717/ peerj.5914\#supplemental-information.

\section{REFERENCES}

Aspöck U. 2002. Phylogeny of the Neuropterida (Insecta: Holometabola). Zoologica Scripta 31(1):51-55 DOI 10.1046/j.0300-3256.2001.00087.x.

Avise JC, Arnold J, Ball RM, Bermingham E, Lamb T, Neigel JE, Reeb CA, Saunders NC. 1987. Intraspecific phylogeography: the mitochondrial DNA bridge between population genetics and systematics. Annual Review of Ecology and Systematics 18(1):489-522

DOI 10.1146/annurev.es.18.110187.002421.

Beard CB, Hamm DM, Collins FH. 1993. The mitochondrial genome of the mosquito Anopheles gambiae: DNA sequence, genome organization, and comparisons with mitochondrial sequences of other insects. Insect Molecular Biology 2(2):103-124

DOI 10.1111/j.1365-2583.1993.tb00131.x.

Beckenbach AT, Stewart JB. 2008. Insect mitochondrial genomics 3: the complete mitochondrial genome sequences of representatives from two neuropteroid orders: a dobsonfly (order Megaloptera) and a giant lacewing and an owlfly (order Neuroptera). Genome 52(1):31-38 DOI 10.1139/G08-098.

Bergsten J. 2005. A review of long-branch attraction. Cladistics 21(2):163-193 DOI 10.1111/j.1096-0031.2005.00059.x.

Bernt M, Donath A, Jühling F, Externbrink F, Florentz C, Fritzsch G, Pütz J, Middendorf M, Stadler PF. 2013. MITOS: improved de novo metazoan mitochondrial genome annotation. Molecular Phylogenetics and Evolution 69(2):313-319 DOI 10.1016/j.ympev.2012.08.023.

Boore JL. 1999. Animal mitochondrial genomes. Nucleic Acids Research 27(8):1767-1780 DOI 10.1093/nar/27.8.1767.

Boore JL, Lavrov DV, Brown WM. 1998. Gene translocation links insects and crustaceans. Nature 392(6677):667-668 DOI 10.1038/33577.

Boyce TM, Zwick ME, Aquadro CF. 1989. Mitochondrial DNA in the bark weevils: size, structure and heteroplasmy. Genetics 123(4):825-836.

Burland TG. 2000. DNASTAR's Lasergene sequence analysis software. In: Misener S, Krawetz SA, eds. Bioinformatics Methods and Protocols. Methods in Molecular Biology. Totowa: Humana Press, 71-91.

Cameron SL. 2014a. Insect mitochondrial genomics: implications for evolution and phylogeny. Annual Review of Entomology 59(1):95-117 DOI 10.1146/annurev-ento-011613-162007.

Cameron SL. 2014b. How to sequence and annotate insect mitochondrial genomes for systematic and comparative genomics research. Systematic Entomology 39(3):400-411 DOI 10.1111/syen.12071.

Cameron SL, Beckenbach AT, Dowton M, Whiting MF. 2006. Evidence from mitochondrial genomics on interordinal relationships in insects. Arthropods Systematics \& Phylogeny 64(1):27-34. 
Cameron SL, Sullivan J, Song H, Miller KB, Whiting MF. 2009. A mitochondrial genome phylogeny of the Neuropterida (lacewings, alderflies and snakeflies) and their relationship to the other holometabolous insect orders. Zoologica Scripta 38(6):575-590 DOI 10.1111/j.1463-6409.2009.00392.x.

Cameron SL, Whiting MF. 2008. The complete mitochondrial genome of the tobacco hornworm, Manduca sexta (Insecta: Lepidoptera: Sphingidae) and an examination of mitochondrial gene variability within butterflies and moths. Gene 408(1-2):112-123 DOI 10.1016/j.gene.2007.10.023.

Castresana J. 2000. Selection of conserved blocks from multiple alignments for their use in phylogenetic analysis. Molecular Biology and Evolution 17(4):540-552 DOI 10.1093/oxfordjournals.molbev.a026334.

Cheng CH, Gai YH, Zhang W, Shao LL, Hao JS, Yang Q. 2014. The complete mitochondrial genome of the Hybris subjacens (Neuroptera: Ascalaphidae). Mitochondrial DNA 25(2):109-110 DOI 10.3109/19401736.2013.786708.

Cheng CH, Sun X, Gai Y, Hao J. 2015. The complete mitochondrial genome of the Epacanthaclisis banksi (Neuroptera: Myrmeleontidae). Mitochondrial DNA 26(6):821-822 DOI 10.3109/19401736.2013.855910.

Cheng XF, Zhang LP, Yu DN, Storey KB, Zhang JY. 2016. The complete mitochondrial genomes of four cockroaches (Iinsecta: Bblattodea) and phylogenetic analyses within cockroaches. Gene 586(1):115-122 DOI 10.1016/j.gene.2016.03.057.

Clary DO, Wolstenholme DR. 1985. The mitochondrial DNA molecular of Drosophila yakuba: nucleotide sequence, gene organization, and genetic code. Journal of Molecular Evolution 22(3):252-271 DOI 10.1007/bf02099755.

Du C, Zhang LF, Lu T, Ma JN, Zeng CJ, Yue BS, Zhang XY. 2017. Mitochondrial genomes of blister beetles (Coleoptera, Meloidae) and two large intergenic spacers in Hycleus genera. BMC Genomics 18(1):698 DOI 10.1186/s12864-017-4102-y.

Engel MS, Winterton SL, Breitkreuz LCV. 2018. Phylogeny and evolution of Nneuropterida: where have wings of lace taken us? Annual Review of Entomology 63(1):531-551 DOI 10.1146/annurev-ento-020117-043127.

Erler S, Ferenz HJ, Moritz RFA, Kaatz HH. 2010. Analysis of the mitochondrial genome of Schistocerca gregaria (Orthoptera: Acrididae). Biological Journal of the Linnean Society 99(2):296-305 DOI 10.1111/j.1095-8312.2009.01365.x.

Fenn JD, Cameron SL, Whiting MF. 2007. The complete mitochondrial genome sequence of the Mormon cricket (Anabrus simplex: Tettigoniidae: Orthoptera) and an analysis of control region variability. Insect Molecular Biology 16(2):239-252 DOI 10.1111/j.1365-2583.2006.00721.x.

Francino MP, Ochman H. 1997. Strand asymmetries in DNA evolution. Trends in Genetics 13(6):240-245 DOI 10.1016/S0168-9525(97)01118-9.

Grant JR, Stothard P. 2008. The CG View Server: a comparative genomics tool for circular genomes. Nucleic Acids Research 36(Web Server):W181-W184 DOI 10.1093/nar/gkn179.

Hanada T, Suzuki T, Yokogawa T, Takemoto-Hori C, Sprinzl M, Watanabe K. 2001. Translation ability of mitochondrial tRNAs-Ser with unusual secondary structures in an in vitro translation system of bovine mitochondria. Genes to Cells 6(12):1019-1030 DOI 10.1046/j.1365-2443.2001.00491.x.

Haring E, Aspöck U. 2004. Phylogeny of the Neuropterida: a first molecular approach. Systematic Entomology 29(3):415-430 DOI 10.1111/j.0307-6970.2004.00263.x.

Haruyama N, Mochizuki A, Sato Y, Naka H, Nomura M. 2011. Complete mitochondrial genomes of two green lacewings, Chrysoperla nipponensis (Okamoto, 1914) and 
Apochrysa matsumurae Okamoto, 1912 (Neuroptera: Chrysopidae). Molecular Biology Reports 38(5):3367-3373 DOI 10.1007/s11033-010-0444-0.

Hassanin A, Leger N, Deutsch J. 2005. Evidence for multiple reversals of asymmetric mutational constraints during the evolution of the mitochondrial genome of metazoa, and consequences for phylogenetic inferences. Systematic Biology 54(2):277-298

DOI 10.1080/10635150590947843.

He K, Chen Z, Yu DN, Zhang JY. 2012. The complete mitochondrial genome of Chrysopa pallens (Insecta, Neuroptera, Chrysopidae). Mitochondrial DNA 23(5):373-375 DOI 10.3109/19401736.2012.696631.

Huelsenbeck JP. 1995. The robustness of two phylogenetic methods: four-taxon simulations reveal a slight superiority of maximum likelihood over neighbor joining. Molecular Biology and Evolution 12(5):843-849 DOI 10.1093/oxfordjournals.molbev.a040261.

Huelsenbeck JP, Hillis DM. 1993. Success of phylogenetic methods in the four-taxon case. Systematic Biology 42(3):247-264 DOI 10.1093/sysbio/42.3.247.

Jia W, Higgs PG. 2008. Codon usage in mitochondrial genomes: distinguishing context-dependent mutation from translational selection. Molecular Biology and Evolution 25(2):339-351 DOI 10.1093/molbev/msm259.

Jiang YL, Garzón-Orduña IJ, Winterton SL, Yang F, Liu XY. 2017. Phylogenetic relationships among tribes of the green lacewing subfamily Chrysopinae recovered based on mitochondrial phylogenomics. Scientific Reports 7(1):7218 DOI 10.1038/s41598-017-07431-1.

Kumar S, Stecher G, Tamura K. 2016. Mega 7: molecular evolutionary genetics analysis version 7.0 for bigger datasets. Molecular Biology and Evolution 33(7):1870-1874 DOI 10.1093/molbev/msw054.

Lan XE, Chen S, Li FH, You P. 2016. The complete mitochondrial genome of Bullanga Florida (Neuroptera: Myrmeleontidae). Mitochondrial DNA Part B 1(1):632-634 DOI 10.1080/23802359.2016.1214548.

Lanfear R, Calcott B, Ho SYW, Guindon S. 2012. PartitionFinder: combined selection of partitioning schemes and substitution models for phylogenetic analyses. Molecular Biology and Evolution 29(6):1695-1701 DOI 10.1093/molbev/mss020.

Li H, Gao JY, Liu HY, Liu H, Liang AP, Zhou XG, Cai WZ. 2011. The architecture and complete sequence of mitochondrial genome of an assassin bug Agriosphodrus dohrni (Hemiptera: Reduviidae). International Journal Biological Science 7(6):792-804 DOI 10.7150/ijbs.7.792.

Li H, Liu HY, Song F, Shi AM, Zhou XG, Cai WZ. 2012a. Comparative mitogenomic analysis of damsel bugs representing three tribes in the family Nabidae (Insecta: Hemiptera). PLOS ONE 7(9):e45925 DOI 10.1371/journal.pone.0045925.

Li H, Liu H, Shi AM, Štys P, Zhou XG, Cai WZ. 2012b. The complete mitochondrial genome and novel gene arrangement of the unique-headed bug Stenopirates sp. (Hemiptera: Enicocephalidae). PLOS ONE 7(1):e29419 DOI 10.1371/journal.pone.0029419.

Li Q, Wei S, Shi M, Chen XX. 2015. Complete mitochondrial genome of Neochauliodes bowringi (MacLachlan) (Megaloptera: Corydalidae). Mitochondrial DNA 26(1):112-113 DOI 10.3109/19401736.2013.803542.

Liu QN, Chai XY, Bian DD, Zhou CL, Tang BP. 2015. The complete mitochondrial genome of Plodia interpunctella (Lepidoptera: Pyralidae) and comparison with other pyraloidea insects. Genome 59(1):37-49 DOI 10.1139/gen-2015-0079.

Ma Y, He K, Yu PP, Yu DN, Cheng XF, Zhang JY. 2015. The complete mitochondrial genomes of three bristletails (Insecta: Archaeognatha): the paraphyly of Machilidae and insights into Archaeognathan phylogeny. PLOS ONE 10(1):e0117669 DOI 10.1371/journal.pone.0117669. 
McMahon DP, Hayward A, Kathirithamby J. 2009. The mitochondrial genome of the 'twisted-wing parasite' Mengenilla australiensis (Insecta, Strepsiptera): a comparative study. BMC Genomics 10(1):603 DOI 10.1186/1471-2164-10-603.

Mitchell SE, Cockburn AF, Seawright JA. 1993. The mitochondrial genome of Anopheles quadrimaculatus species A: complete nucleotide sequence and gene organization. Genome 36(6):1058-1073 DOI 10.1139/g93-141.

Mueller RL, Boore JL. 2005. Molecular mechanisms of extensive mitochondrial gene rearrangement in plethodontid salamanders. Molecular Biology and Evolution 22(10):2104-2112 DOI 10.1093/molbev/msi204.

Negrisolo E, Babbucci M, Patarnello T. 2011. The mitochondrial genome of the ascalaphid owlfly Libelloides macaronius and comparative evolutionary mitochondriomics of neuropterid insects. BMC Genomics 12(1):221 DOI 10.1186/1471-2164-12-221.

Nardi F, Carapelli A, Fanciulli PP, Dallai R, Frati F. 2001. The complete mitochondrial DNA sequence of the basal hexapod Tetrodontophora bielanensis: evidence for heteroplasmy and tRNA translocations. Molecular Biology and Evolution 18:1293-1304 DOI 10.1093/oxfordjournals.molbev.a003914.

Ojala D, Montoya J, Attardi G. 1981. tRNA punctuation model of RNA processing in human mitochondria. Nature 290(5806):470-474 DOI 10.1038/290470a0.

Perna NT, Kocher TD. 1995. Patterns of nucleotide composition at fourfold degenerate sites of animal mitochondrial genomes. Journal of Molecular Evolution 41(3):353-358 DOI $10.1007 / \mathrm{bf} 01215182$.

Peters RS, Meusemann K, Petersen M, Mayer C, Wilbrandt J, Ziesmann T, Donath A, Kjer KM, Aspöock U, Aspöock H, Aberer A, Stamatakis A, Friedrich F, Höunefeld F, Niehuis O, Beutel RG, Misof B. 2014. The evolutionary history of holometabolous insects inferred from transcriptome based phylogeny and comprehensive morphological data. BMC Evolutionary Biology 14(1):52 DOI 10.1186/1471-2148-14-52.

Philippe H. 2000. Opinion: long branch attraction and protist phylogeny. Protist 151:307-316.

Philippe H, Zhou Y, Brinkmann H, Rodrigue N, Delsuc F. 2005. Heterotachy and long-branch attraction in phylogenetics. BMC Evolutionary Biology 5(1):50

DOI 10.1186/1471-2148-5-50.

Ronquist F, Teslenko M, Mark PVD, Ayres DL, Darling A, Höhna S, Larget B, Liu L, Suchard MA, Huelsenbeck JP. 2012. MrBayes 3.2: efficient Bayesian phylogenetic inference and model choice across a large model space. Systematic Biology 61(3):539-542

DOI 10.1093/sysbio/sys029.

Salvato P, Simonato M, Battisti A, Negrisolo E. 2008. The complete mitochondrial genome of the bag-shelter moth Ochrogaster lunifer (Lepidoptera, Notodontidae). BMC Genomics 9(1):331 DOI 10.1186/1471-2164-9-331.

Sheffield NC, Song H, Cameron SL, Whiting MF. 2008. A comparative analysis of mitochondrial genomes in Coleoptera (Arthropoda: Insecta) and genome descriptions of six new beetles. Molecular Biology and Evolution 25(11):2499-2509 DOI 10.1093/molbev/msn198.

Simon C, Buckley TR, Frati F, Stewart JB, Beckenbach AT. 2006. Incorporating molecular evolution into phylogenetic analysis, and a new compilation of conserved polymerase chain reaction primers for animal mitochondrial DNA. Annual Review of Ecology Evolution and Systematics 37(1):545-579 DOI 10.1146/annurev.ecolsys.37.091305.110018.

Song N, Lin A, Zhao X. 2018. Insight into higher-level phylogeny of Neuropterida: evidence from secondary structures of mitochondrial rRNA genes and mitogenomic data. PLOS ONE 13(1):e0191826 DOI 10.1371/journal.pone.0191826. 
Stange LA. 2004. A systematic catalog, bibliography and classification of the world antlions (Insecta: Neuroptera: Myrmeleontidae). Vol. 74. Gainesville: Memoirs of the American Entomological Institute, 1-565.

Stamatakis A. 2014. RAxML version 8: a tool for phylogenetic analysis and post-analysis of large phylogenies. Bioinformatics 30(9):1312-1313 DOI 10.1093/bioinformatics/btu033.

Stewart JB, Beckenbach AT. 2003. Phylogenetic and genomic analysis of the complete mitochondrial DNA sequence of the spotted asparagus beetle Crioceris duodecimpunctata. Molecular Phylogenetics and Evolution 26(3):513-526 DOI 10.1016/S1055-7903(02)00421-9.

Thompson JD, Gibson TJ, Plewniak F, Jeanmougin F, Higgins DG. 1997. The CLUSTAL_X windows interface: flexible strategies for multiple sequence alignment aided by quality analysis tools. Nucleic Acids Research 25(24):4876-4882 DOI 10.1093/nar/25.24.4876.

Wang YY, Liu XY, Winterton SL, Yang D. 2012. The first mitochondrial genome for the fishfly subfamily Chauliodinae and implications for the higher phylogeny of Megaloptera. PLOS ONE 7(10):e47302 DOI 10.1371/journal.pone.0047302.

Wang YY, Liu XY, Winterton SL, Yan Y, Chang WC, Yang D. 2013. Comparative mitogenomic analysis reveals sexual dimorphism in a rare montane lacewing (Insecta: Neuroptera: Ithonidae). PLOS ONE 8(12):e83986 DOI 10.1371/journal.pone.0083986.

Wang YY, Liu XY, Garzón-Orduña IJ, Winterton SL, Yan Y, Aspöck U, Aspöck H, Yang D. 2017. Mitochondrial phylogenomics illuminates the evolutionary history of Neuropterida. Cladistics 33(6):617-636 DOI 10.1111/cla.12186.

Wang YY, Liu XY, Yang D. 2016. The complete mitochondrial genome of a fishfly, Dysmicohermes ingens (Chandler) (Megaloptera: Corydalidae: Chauliodinae). Mitochondrial DNA Part A 27(2):1092-1093 DOI 10.3109/19401736.2014.930837.

Winterton SL, Hardy NB, Wiegmann BM. 2010. On wings of lace: phylogeny and Bayesian divergence time estimates of Neuropterida (Insecta) based on morphological and molecular data. Systematic Entomology 35(3):349-378 DOI 10.1111/j.1365-3113.2010.00521.x.

Winterton SL, Lemmon AR, Gillung JP, Garzon IJ, Badano D, Bakkes DK, Breitkreuz LCV, Engel MS, Lemmon EM, Liu X, Machado RJP, Skevington JH, Oswald JD. 2018. Evolution of lacewings and allied orders using anchored phylogenomics (Neuroptera, Megaloptera, Raphidioptera). Systematic Entomology 43(2):330-354 DOI 10.1111/syen.12278.

Wolstenholme DR. 1992. Animal mitochondrial DNA: structure and evolution. International Review of Cytology 141:173-216 DOI 10.1016/S0074-7696(08)62066-5.

Yan Y, Wang YY, Liu XY, Winterton SL, Yang D. 2014. The first mitochondrial genomes of antlion (Neuroptera: Myrmeleontidae) and split-footed lacewing (Neuroptera: Nymphidae), with phylogenetic implications of Myrmeleontiformia. International Journal of Biological Sciences 10(8):895-908 DOI 10.7150/ijbs.9454.

Yu DJ, Xu L, Nardi F, Li JG, Zhang RJ. 2007. The complete nucleotide sequence of the mitochondrial genome of the oriental fruit fly, Bactrocera dorsalis (Diptera: Tephritidae). Gene 396(1):66-74 DOI 10.1016/j.gene.2007.02.023.

Zhang LL, Yang J. 2017. The mitochondrial genome of Gatzara jezoensis (Neuroptera: Myrmeleontidae) and phylogenetic analysis of Neuroptera. Biochemical Systematics and Ecology 71:230-235 DOI 10.1016/j.bse.2017.02.009.

Zhang LP, Yu DN, Storey KB, Cheng HY, Zhang JY. 2018. Higher tRNA gene duplication in mitogenomes of praying mantises (Dictyoptera, Mantodea) and the phylogeny within 
Mantodea. International Journal of Biological Macromolecules 111:787-795

DOI 10.1016/j.ijbiomac.2018.01.016.

Zhang J, Wang XL. 2016. The complete mitochondrial genome of Myrmeleon immanis Walker, 1853 (Neuroptera: Myrmeleontidae). Mitochondrial DNA Part A 27(2):1439-1440 DOI 10.3109/19401736.2014.953082.

Zhang JY, Zhou CF, Gai YH, Song DX, Zhou KY. 2008. The complete mitochondrial genome of Parafronurus youi (Insecta: Ephemeroptera) and phylogenetic position of the Ephemeroptera. Gene 424(1-2):18-24 DOI 10.1016/j.gene.2008.07.037.

Zhang JY, Song DX, Zhou KY. 2008. The complete mitochondrial genome of the bristletail Pedetontus silvestrii (Archaeognatha: Machilidae) and an examination of mitochondrial gene variability within four bristletails. Annals of the Entomological Society of America 101(6):1131-1136 DOI 10.1603/0013-8746-101.6.1131.

Zhao J, Li H, Winterton SL, Liu ZQ. 2013. Ancestral gene organization in the mitochondrial genome of Thyridosmylus langii (McLachlan, 1870) (Neuroptera: Osmylidae) and implications for lacewing evolution. PLOS ONE 8(5):e62943 DOI 10.1371/journal.pone.0062943.

Zhao Y, Chen YJ, Zhao J, Liu ZQ. 2016. First complete mitochondrial genome from the brown lacewings (Neuroptera: Hemerobiidae). Mitochondrial DNA Part A 27(4):2763-2764 DOI 10.3109/19401736.2015.1053054.

Zhao YY, Zhang HL, Zhang YH. 2017. Complete mitochondrial genome of Neochauliodes parasparsus (Megaloptera: Corydalidae) with phylogenetic consideration. Biochemical Systematics and Ecology 70:192-199 DOI 10.1016/j.bse.2016.12.002. 